\section{PATENT \\ FORAMEN OVALE}

\title{
Percutaneous closure of the patent foramen ovale: A cardiological perspective
}

\section{S.C. Brown}

Department of Paediatric Cardiology, University of the Free State, Bloemfontein, South Africa

Address for correspondence:

Prof S.C. Brown

Department Paediatric Cardiology G69

University of the Free State

PO Box 339

Bloemfontein

9300

South Africa

Email:

gnpdscb@ufs.ac.za

\section{INTRODUCTION}

Until recently, the patent foramen ovale (PFO) was considered a foetal remnant and of limited clinical importance. It has now been recognised that patency of the foramen ovale results in problems exclusively encountered in adults, especially stroke and migraine. Improvements in methods of closure and diagnosis have become available for clinical practice and focused renewed attention on the risks and management of patients with a PFO.

\section{ANATOMICAL ISSUES}

In a healthy population, up to $27 \%$ may have a PFO.(1,2) PFOs are anatomically more complex than atrial septal defects and consist of two anatomically and dynamically different components - a thick rigid septum secundum and a thin mobile septum primum. ${ }^{(3)}$ Lack of fusion of these two structures results in a patent foramen. The length of the tunnel formed by this interaction is determined by the extent of overlap, whilst the width (diameter) is determined by the area of non-fusion between these two components (Figure I). Atrial septal aneurysms are frequently associated with PFOs and may bulge into either the left atrium, right atrium or both atria.

\section{ABSTRACT}

\begin{abstract}
A patent foramen is commonly found in the general population. Evidence exists that a patent foramen ovale (PFO) and atrial septal aneurysm are strongly associated with cryptogenic stroke. Associations with migraine have also been described, but the status of cause and effect is less clear. Management of PFO is controversial and no form of therapy has been properly evaluated. PFO closure devices are readily available and can be safely and effectively implanted percutaneously. Complication rates are low and symptoms are improved in most patients. At present, there is a lack of guidelines for the treatment of PFO and results of prospective randomised trials are eagerly awaited. SAHeart 20 I0; 7:264-27।
\end{abstract}

Venous flow is channelled towards the fossa ovalis due to the orientation of the inferior vena cava. A prominent Eustachian valve is commonly observed in the presence of a PFO. This may further direct inferior caval flow towards the fossa ovalis.

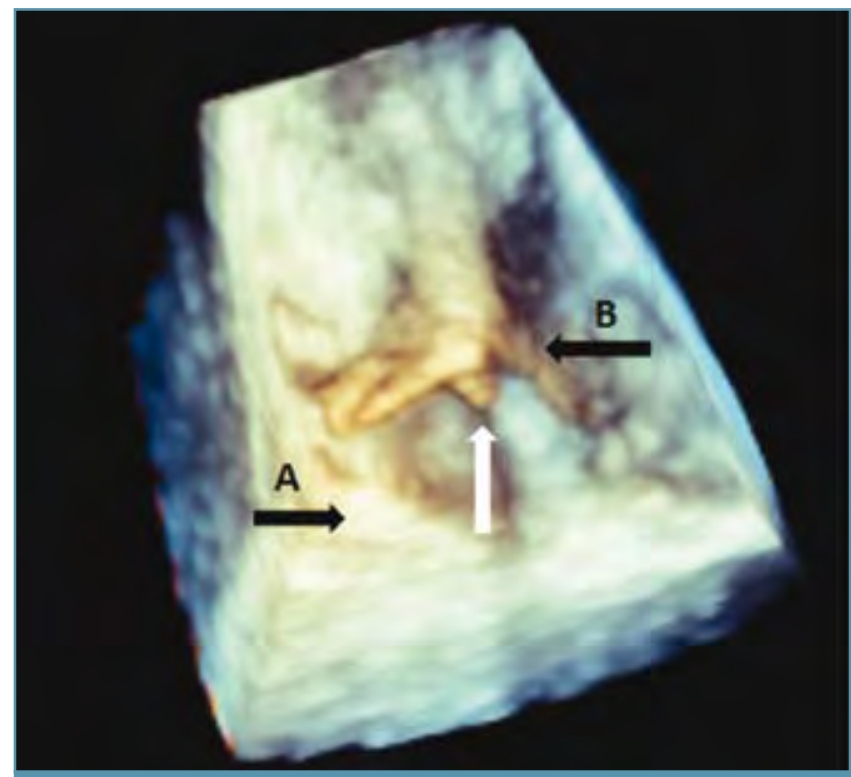

FIGURE I: Three Dimensional TEE demonstrating PFO anatomy: The thick septum secundum can be seen (arrow A) overlapped by the thin septum primum (arrow B). A guide wire (white arrow) is demonstrated passing through and lifting the long channel, exiting at the opening in the left atrial aspect due to lack of fusion of the septum primum and secundum. 

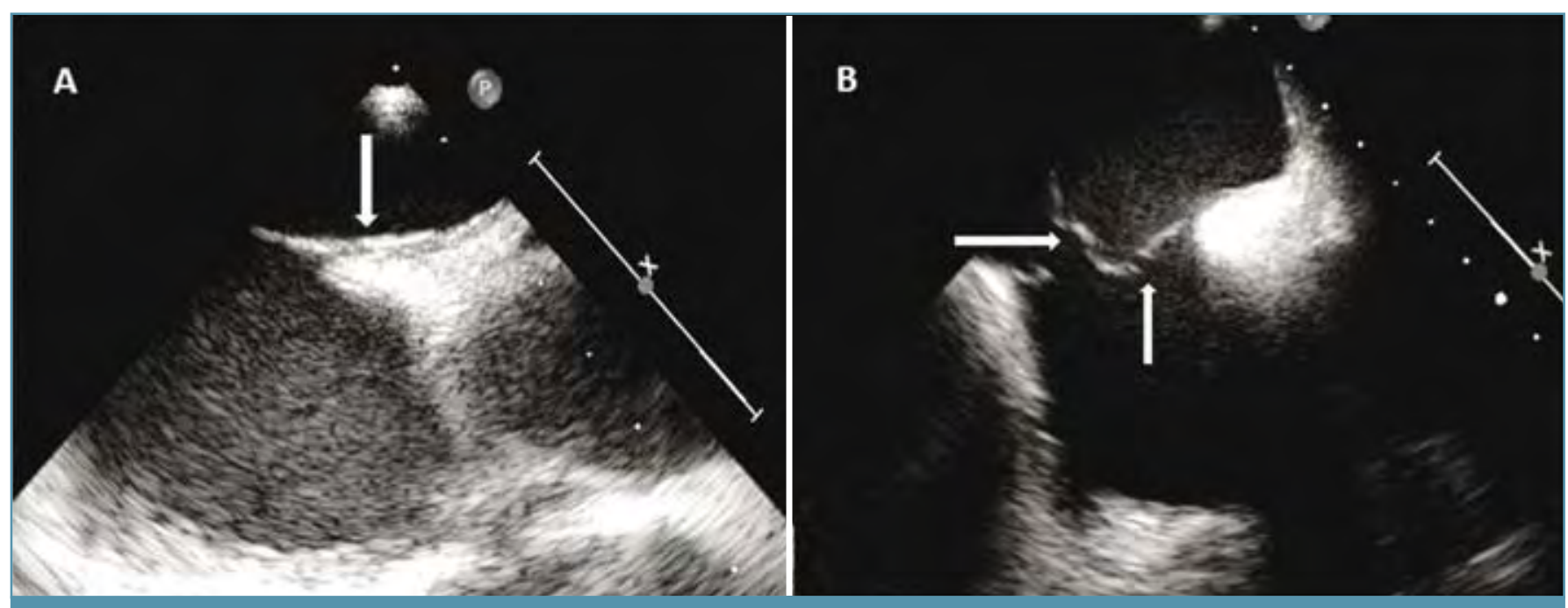

FIGURE 2: TEE images of PFO. In A, a long tunnel-like PFO is demonstrated with a thin septum secundum overlapping (arrow) a thick septum secundum. B shows an atrial septal aneurysm with multiple perforations (arrows).

All of these factors should be taken into consideration during diagnosis and closure of a PFO. Rigid devices not taking the dynamic interaction of the septae into consideration may "splint" the defect and result in either incomplete epithelialisation or residual shunting. Diagnostic consideration should also be given to anatomical and physiological factors. For example, the presence of a prominent Eustachian valve may have an influence on the demonstration of a PFO since contrast injection in the veins of the upper limbs may not yield a positive bubble test due its effect on direction of flow, whilst it may show a large shunt in the same patient if injected via a lower limb vein. Device struts may also be caught in the Eustachian valve, preventing successful closure. The patent foramen ovale is clearly a complex structure and attention should be paid to the anatomical substrate during diagnosis and pecutaneous management of the PFO since it may have a profound influence on risks and outcomes. ${ }^{(4)}$

\section{DETECTING A PFO}

Transthoracic Echocardiography (TTE)

TTE is generally used as a screening test to diagnose PFO and it is important to recognise that a negative TTE does not rule out a PFO. In patients with good echocardiographic windows, anatomical detail of the PFO may be delineated. However, even with harmonic imaging, it has lower sensitivity and specificity $(76.5 \%$ and $79.4 \%$, respectively) than transoesophageal echocardiography. ${ }^{(5,6)}$
Using the Valsalva manoeuvre alone or in combination with agitated saline or other contrast agents, results for detection of PFO by means of TTE can be markedly improved. ${ }^{(7-10)}$

\section{Transcranial Doppler (TCD)}

TCD is highly sensitive and specific for the diagnosis of right to left shunts and is the preferred screening tool.(I) TCD does not cause any discomfort to patients and requires no sedation. However, TCD does not differentiate PFO from other causes of right to left shunts (e.g. arteriovenous fistula) neither does it provide any information regarding anatomy or especially, the presence of an atrial septal aneurysm. ${ }^{(12)}$

\section{Transoesophageal Echocardiography (TEE)}

TEE is considered the gold standard for the diagnosis of PFO and delineation of the underlying morphology (Figure 2). It is more invasive than the other methods of detection and patients need to be sedated. Contrast echo, with or without the Valsalva manoeuvre, is helpful in the assessment of a PFO. Bubbles can be seen crossing the PFO during the release phase of the Valsalva manoeuvre as blood kept out of the thorax rushes back into the right atrium. TEE is especially helpful to ensure accurate and safe placement of transcatheter devices. In patients with cryptogenic stroke, it is recommended that TEE should routinely be included in the assessment of such patients since it also allows other cardiovascular causes of stroke to be detected. ${ }^{(13-15)}$ 
Overall, there is a lack of standardisation of methods to demonstrate size and significance of PFOs as well as quantification of the shunt. The number of contrast bubbles in the left atrium is sometimes employed, but does not necessarily correlate with the magnitude of the shunt. ${ }^{(16-18)}$ Furthermore, superior caval flow, which is directed towards the tricuspid valve may be prevented from crossing a PFO due to the effect of Eustachian valve streaming which influences the reliability of detection of a PFO's shunting and the injection of echocardiographic contrast into a lower limb vein may prove more accurate. ${ }^{(19,20)}$ Also, since patients are commonly sedated to perform TEE, the Valsalva manoeuvre may be difficult to perform. The classification of atrial septal aneurysm also varies, but tissue movement in excess of $10 \mathrm{~mm}$ from the septal plane is helpful in the diagnosis. ${ }^{(21-23)}$ Atrial septal aneurysm is frequently associated with PFO as well as other cardiac abnormalities. ${ }^{(24,25)}$ Other imaging modalities such as intra-cardiac echocardiography (ICE) are sometimes employed during implantation of devices, although most operators still prefer TEE.

\section{PFO AND STROKE}

Stroke is one of the leading causes of morbidity and mortality worldwide. Cryptogenic stroke accounts for up to $40 \%$ of causes of ischaemic stroke and is essentially diagnosed if, after extensive investigation, no other cause of infarction can be identified. ${ }^{(26)}$ The exact mechanism by which PFO causes stroke is ascribed to paradoxical embolism by way of a right to left shunt. The vast majority of studies have reported an increased prevalence of PFO ranging from $31-77 \%$ in patients with cryptogenic stroke compared to less than $25 \%$ in patients with stroke of known cause.

The presence of an atrial septal aneurysm increases risk: PFO with atrial septal aneurysms occurred significantly more (odds ratio 3.65; 95\% Cl: 1.64-8.13) in patients than in controls. ${ }^{(27-30)}$ Although this association with stroke has been more convincingly established in patients younger than 55 years of age, recent studies have also demonstrated significant associations in older patients. . $^{(13,28,31,32)}$ In addition, a recent publication illustrated that the co-existence of a PFO with atrial septal aneurysm play an important pathogenic role in the severity of white matter lesions in these patients (odds ratio $2.4 ; 95 \% \mathrm{Cl}$ : I.I I-5.17) compared to stroke patients without septal abnormalities $(p=0.026)$. ${ }^{(33)}$ The presence of both PFO and atrial septal aneurysm is also a significant predictor of an increased risk for recurrent stroke - hazard ratio 4.17 (95\% Cl: | .47- I I.84) with a risk of $15.2 \%$ compared to $4.2 \%$ in the absence of both. ${ }^{(16)}$ TEE is thus recommended for all patients with cryptogenic stroke to identify PFO or other cardiac causes. ${ }^{(14,15)}$

\section{RESULTS OF TRANSCATHETER CLOSURE IN ISCHAEMIC STROKE}

Currently, due to a lack of appropriate randomised controlled clinical trials, no ideal treatment (medical, surgical or percutaneous device implantation) can be recommended. There is also insufficient long-term follow-up data. Several reports have demonstrated the feasibility of percutaneous closure. Small studies, as well as systematic reviews, showed that recurrence rates for stroke after device closure was reduced to between 0 and $5 \%$ (versus $3-12 \%$ with medical therapy) with minimal residual shunting.(10,34-36) Interestingly, some of the recurrent ischaemic episodes occurred in patients where no residual shunts could be detected, probably indicating that other underlying mechanisms are involved in the pathogenesis of stroke.

At present, there are no clearly defined guidelines from any professional society and most state that insufficient evidence exists to make a recommendation. ${ }^{(37)}$ The American Heart Association, American Stroke Association and American College of Chest Physicians as a result encourage physicians to participate in ongoing trials (RESPECT, CLOSURE-I, PC-Trial, CLOSE and Gore REDUCE) to resolve the uncertainties regarding optimal care for these patients. $^{(28,38)}$

\section{MIGRAINE AND PFO}

Right-to-left shunts are more prevalent in patients with migraine. Migraine also occurs more commonly in patients with right-to-left shunt lesions. In addition, PFOs have been demonstrated in 40-72\% of those with migraine. The odds of a patient with migraine having a PFO are 2.5 times greater than the general population and for migraine with aura 3.2 times greater than those without aura. ${ }^{(39-42)}$ Several retrospective, non-randomised trials suggested benefit following PFO closure. However, the only prospective, sham controlled trial (MIST-I) showed negative outcomes for both the primary and secondary endpoints of improvement of migraine headaches. ${ }^{(43)}$ It was concluded that the role of PFO closure for 
the treatment of migraine was unclear. Differences between MIST-I and other studies should be mentioned. Only migraine with aura without history of previous embolic episodes was included, whilst the majority of other studies included patients with migraine and history of embolic stroke. Patients treated in MIST-I all had severe refractory migraine not responding to any other form of treatment and there were controversies regarding the methods of follow-up assessment as well as absence of data regarding the concomitant use of medication.

A current systematic review and meta-analysis of I 306 patients showed complete cure of migraine after PFO closure in 46\% (95\% Cl: 25-67\%) with resolution or significant improvement in $83 \%$ (95\% Cl: 78 -88\%). ${ }^{(44)}$ Similar findings have recently been reported and it has been shown that migraine with aura and high pain intensity at baseline were independent predictors of positive response to PFO closure. The study included patients with and without history of paradoxical embolism.(45) There are ongoing randomised trials, including percutaneous closure of PFO in migraine with aura (PRIMA) and the prospective randomised investigation to evaluate incidence of headache with migraine and PFO using the Amplatzer PFO occluder compared to medical management (PREMIUM).

\section{DIVING AND PFO}

Neurological decompression events occurring when diving with a PFO are reported to have an odds ratio of 2.6 with PFO present in $60 \%$ of patients vs. $36 \%$ in controls. A TEE should be performed in divers when no cause is evident after a neurological decompression incident. ${ }^{(46,47)}$ It is recommended that, if a diver wants to continue diving after a PFO is detected following such an incident, other safety measures including the option of percutaneous device closure, could be considered.

\section{PERCUTANEOUS PFO CLOSURE}

The initial devices used for closure of PFO were based on versions of atrial septal defect closure devices. Various devices have been employed worldwide, but in South Africa the Amplatzer ${ }^{\circledR}$ (AGA Medical, MN, USA), Atriasept $\|^{\circledR}$ (Cardia Eagan, MN, USA) and Solysafe $^{\circledR}$ (Swissimplant AG, Solothurn, Switzerland) devices are available in different diameters (Figure 3). PFO anatomy produces
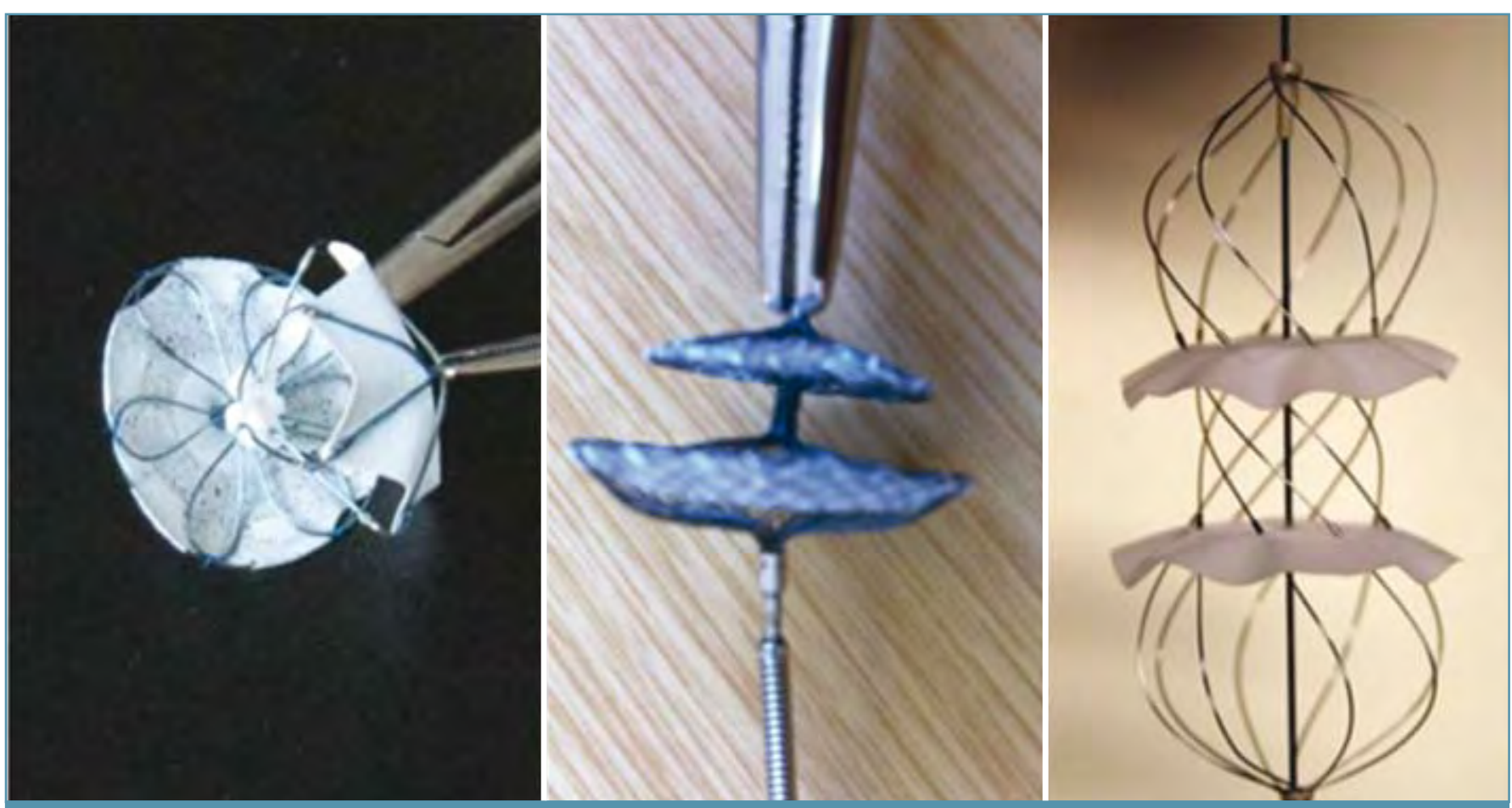

FIGURE 3: PFO closure devices from left to right are:Atriasept $I^{\circledR}$, Amplatzer $^{\circledR}$ and Solysafe ${ }^{\circledR}$. 
unique challenges and appreciation of these characteristics play an important role in the selection of a device.

\section{PROCEDURE}

Technical details have been published but generally it is a relatively simple and quick procedure. ${ }^{(29,35,48-50)}$ In short, percutaneous venous access is gained via the femoral vein and an appropriate long sheath is left in situ after having crossed the PFO into the left atrium. Patients are heparinised and extreme care should be taken to prevent air embolism throughout the procedure. Prophylactic antibiotics are usually given. The procedure may be performed with or without general anaesthesia using one or more of the following for control: fluoroscopy, TEE or ICE. Most operators prefer general anaesthesia and use TEE combined with fluoroscopy. Careful consideration should be given to the morphology of the PFO and surrounding structures when selecting the type and size of a device. Balloon sizing may be required, but this is not generally necessary. ${ }^{(51,52)}$ Presence of atrial septal aneurysms and prominent Eustachian valves may complicate procedures. After selection of an appropriate device, it is deployed in the correct position. Most devices are retrievable and re-useable before release from the delivery mechanism. The device is then released and some are even retrievable at this stage (Figure 4). Patients may be discharged
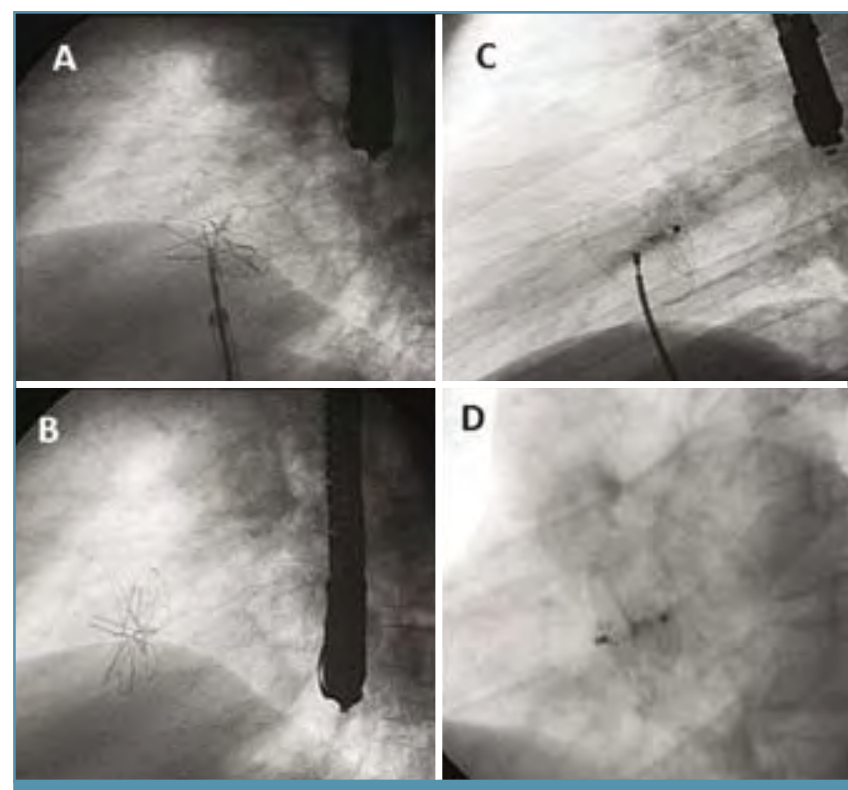

FIGURE 4: Atriasept $\|^{\circledR}$ device with cable of delivery forceps still attached (A) and after release (B).Amplatzer ${ }^{\circledR}$ PFO device attached to delivery cable pre-release (C) and after release (D). on the same day after satisfactory positioning has been confirmed (Figure 5). Clopidogrel is usually prescribed for 4-6 weeks and low dose salicylates for 6 months. Follow-up TEE should be performed 6 months after implantation of a percutaneous PFO device.

Success rates for the procedure range from 98-100\%. In experienced centres with experienced operators, complications are uncommon but minor complications (pain, bleeding at site of catheterisation, transient arrhythmias etc.) occur in up to $7.9 \%$ and major complications (tamponade, infection, thrombus formation) in less than $1.5 \%$ of cases respectively. ${ }^{(10,41,42,53,54)}$ Late erosions into surrounding tissues have been described with all intracardiac devices, but are rare after PFO closure. Residual shunts are common immediately following implantation, but infrequent (5-10\%) after 12 months. ${ }^{(35,55,56)}$

\section{MORE RECENT TRENDS}

Three-dimensional echocardiography may provide improved assistance during assessment, implantation and follow-up of device closure of defects (Figure 6). New devices are being developed specifically for PFO closure - these are less rigid and bulky and should lead to improvement in closure rates with a reduction in complications. ${ }^{(57)}$ Future devices will probably employ less material and metal and target the specific anatomical defect.

\section{CONTROVERSIES AND FOOD FOR THOUGHT}

Percutaneous closure of a PFO can be safely and effectively performed using modern devices. However, the indications for closure are more complex and will be debated for many years to come. Most of the uncertainties are caused by insufficient evidence attributable to the lack of randomised, controlled clinical trials. This is aggravated by the slow recruitment in currently ongoing trials Literature comparing medical and percutaneous management is not available and current opinion is based on observational studies and case-control reviews with its inherent drawbacks.

Compelling evidence exists that PFO with atrial septal aneurysm carry considerable risk. It is more difficult to quantify this risk in the presence of a PFO. The question of cause and effect is still unclear and therefore double standards in management exist. ${ }^{(58-61)}$ Most 


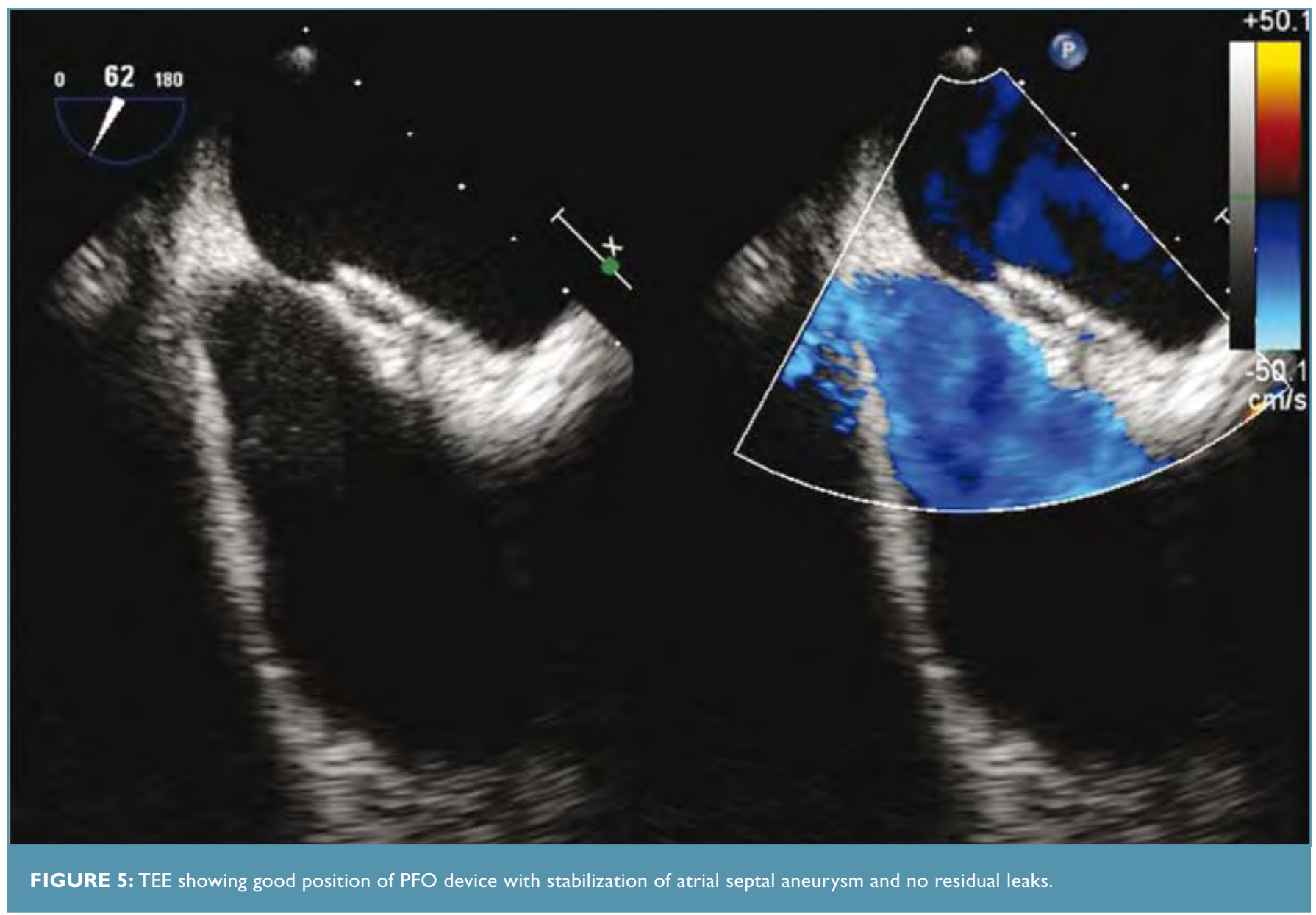

likely, many different mechanisms are involved in causing stroke and migraine in the presence of a PFO and probably PFO closure may benefit only certain subsets of patients. Decisions we make now have an effect upon the future and, as treating physicians, we could end up in difficult situations: We could close defects unnecessarily with the risk of complications while having little effect on prevention of stroke; or alternatively delay closure and face medico-legal risks due to "malpractice" in future years. Add to this a patient who had a stroke and knows that there is a "hole" in his/her heart and one can understand that it makes for an emotional debate.

It is also important to recognise what effects rigid devices may have on intra-cardiac structures. In a thought provoking editorial, McElhinney pointed out that studies have shown aortic regurgitation, erosion and atrio-ventricular block with intra-cardiac devices, sometimes many years after implantation due to the interaction of the devices with the surrounding tissues. He postulated that the

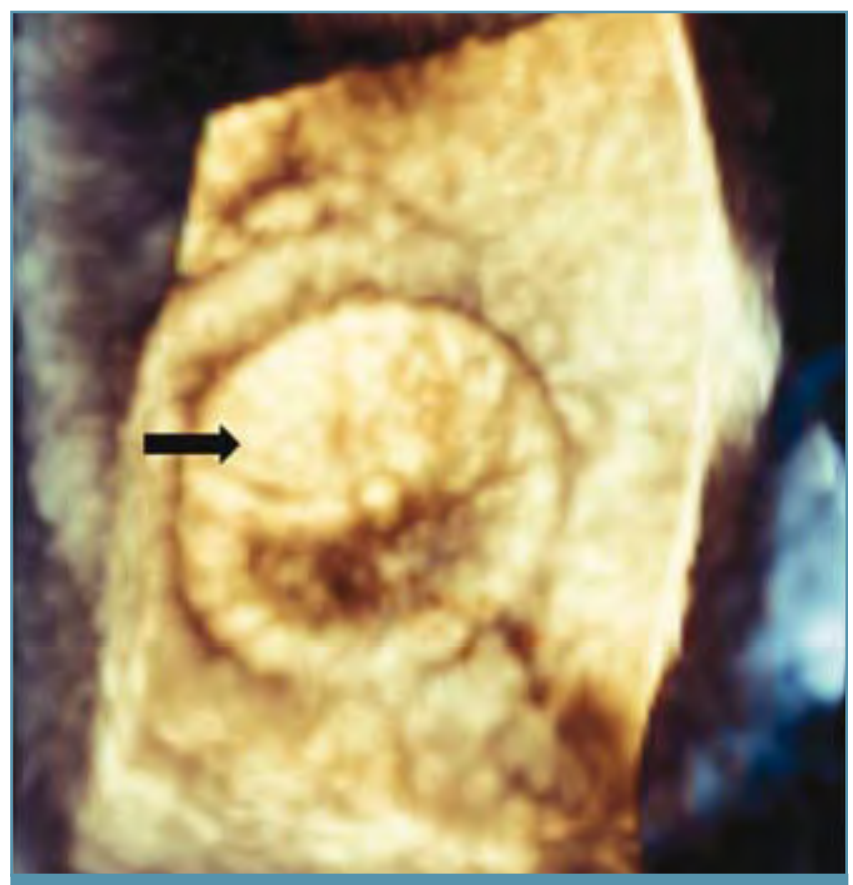

FIGURE 6: Three Dimensional TEE image of PFO closure device: Left atrial disk of closure device in good position against inter-atrial septum. 
future of PFO closure may hinge on these considerations more than other. ${ }^{(62)}$

At present it seems that PFO closure may be of benefit, although unproven, in patients with PFO and atrial septal aneurysm with a history of: cryptogenic stroke (especially if $<55$ years); recurrent deep vein thrombosis and pulmonary embolism; existence of contra-indications to anticoagulation; large shunts; and in commercial divers. These are only suggestions and not recommendations or guidelines. It also emphasises the need for societies to provide clear guidelines to assist treating physicians and bring "closure" to this matter.

\section{CONCLUSION}

PFO is a common congenital anomaly in the general population. In contrast to previously held beliefs that a PFO is an innocent anomaly, it has been found to be more prevalent in patients with cryptogenic stroke and certain forms of migraine. No optimal therapy for PFO in these patients, either medical or interventional, has been identified and future clinical management will depend on clarification of the pathogenesis related to these conditions. Percutaneous closure of a PFO is relatively simple. The devices have been shown to be effective and safe. Evidence for best treatment is lacking and results of randomised, controlled clinical trials are eagerly awaited.

\section{ACKNOWLEDGEMENTS}

The author gratefully acknowledges the assistance of Prof. D.K. Stones during preparation of the manuscript and Dr. J. Harrisberg for the 3-D images.

\section{REFERENCES}

I. Seib G. Incidence of the patent foramen ovale cordis in adult American Whites and American Negroes. Am J Anat. 1934;55:5 I I-525

2. Hagen PT, Scholz DG, Edwards WD. Incidence and size of patent foramen ovale during the first 10 decades of life: An autopsy study of 965 normal hearts. Mayo Clin Proc. 1984;59: 17-20

3. Marshall AC, Lock JE. Structural and compliant anatomy of the patent foramen ovale in patients undergoing transcatheter closure. Am Heart J 2000; 1 40:303-7.

4. Fazio G, Ferro G, Carità P et al. The PFO anatomy evaluation as possible tool to stratify the associated risks and the benefits arising from the closure. Eur J Echocardiogr 2010 Feb 10 [E pub ahead of print]

5. Trevelyan J, Steeds RP. Comparison of transthoracic echocardiography with harmonic imaging with transoesophageal echocardiography for the diagnosis of patent foramen ovale. Postgrad Med J 2006;82:6। 3-4

6. Madala D, Zaraff JG, Hourigan L, et al. Harmonic imaging improves sensitivity at the expense of specificity in the detection of patent foramen ovale. Echocardiography 2004;21:33-6.

7. Clarke NRA, Timperley J, Kelion AD, et al. Transthoracic echocardiography using second harmonic imaging with Valsalva manoeuvre for the detection of right to left shunts. Eur J Echocardiogr 2004;5: 176-81.

8. Kuhl HP, Hoffmann R, Merx MW, et al. Transthoracic echocardiography using second harmonic imaging: diagnostic alternative to transoesophageal echocardiography for the detection of atrial right to left shunt in patients with cerebral embolic events. J Am Coll Cardiol 1999;34:1823-30.

9. Woods TD, Patel A. A critical review of patent foramen detection using saline contrast echocardiography: When bubbles lie. J Am Soc Echocardiogr 2006; 19:215-222.

10. Mareedu RK, Shah MS, Mesa JE, et al. Percutaneous closure of patent foramen ovale: A case series and literature review. Clin Med Res 2007;5:2 18-26.

11. Del Sette M, Dinia L, Rizzi D,et al. Diagnosis of right-to-left shunt with transcranial Doppler and vertebrobasillar recording. Stroke 2007;38:2254-6.

12. Jauss M,Zanette E. Detection of right-to-left shunt with ultrasound contrast agent and transcranial Doppler sonography. Cerebrovasc Dis 2000; 1 0:490-6.

13. Mesa D, Ruiz M, Delgado M, et al. Prevalence of patent foramen ovale determined by transoesophageal echocardiography in patients with cryptogenic stroke aged 55 years or older. Same as younger patients? Rev Esp Cardiol 20 I 0;63:3 I 5-22.

14. Gupta N, Lau C, Al-Dehneh A, et al. Importance of performing transoesophageal echocardiography in acute stroke patients older than fifty. Echocardiography 2010 Jun 4. [Epub ahead of print].

15. Knebel F, Masuhr F, von Hausen W, et al. Transoesophageal echocardiography in patients with cryptogenic cerebral ischaemia. Cardiovasc Ultrasoun 20 I 0;7: 15

16. Mas JL, Arquizan C, Lamy C, et al. Recurrent cerebrovascular events associated with patent foramen ovale, atrial septal aneurysm or both. N Engl J Med 200 I: 345:1740-6.

17. Schuchlenz HW, Weihs W, Beitzke A,et al. Transoesophageal echocardiography for quantifying size of patent foramen ovale in patients with cryptogenic cerebrovascular events. Stroke 2002;33:293-296.

18. Schuchlenz HW, Weihs W, Horner S, et al. The association between the diameter of a patent foramen ovale and the risk of embolic cerebrovascular events. Am J Med 2000; 109:456-62.

19. Gin KG, Huckell VF, Pollick C. Femoral vein delivery of contrast medium enhances transthoracic echocardiographic detection of patent foramen ovale. J Am Coll Cardiol 1993;22:1994-2000.

20. Schuchlenz HW, Saurer G, Weihs W, et al. Persisting Eustachian valve in adults: relation to patent foramen ovale and cerebrovascular events. J Am Soc Echocardiogr 2004; 17:231-3. 
21. Mügge A, Daniel WG, Angermann C, et al. Atrial septal aneurysm in adult patients: a multicentre study using transthoracic and transoesophageal echocardiography. Circulation 1995;91:2785-92.

22. Hassan A, Parvez A, Ajmal MR. Patent foramen ovale - clinical significance. JIACM 2004;5:339-44.23. Puvaneswary M, Singham T, Bastian B. Atrial septal aneurysm: $\mathrm{MRI}$ and echocardiography correlation. Australas Radiol 2003;47:468-7।

24. Olivares-Reyes A, Chan S, Lazar EJ, et al. Atrial septal aneurysm: A new classification in two hundred and five adults. J Am Soc Echocardiogr 1997; 10:644-56.

25. Hanley PC, Tajik AJ, Hynes JK, et al. Diagnosis and classification of atrial septal aneurysm by two-dimensional echocardiography: Report of 80 consecutive cases. J Am Coll Cardiol 985;6:1370-82.

26. Adams HP, Bendixen BH, Kapelle LJ, et al. Classification of subtype of acute ischaemic stroke. Definitions for use in a multi-centre clinical trial.TOAST, Trial of Org 10172 in acute stroke treatment. Stroke 1993;24:35-41.

27. Overell JR, Bone I, Lees KR. Inter-atrial septal abnormalities and stroke - a metaanalysis of case-control studies. Neurology 2000;55:1 $172-9$.

28. O'Gara PT, Messe SR, Tuzcu EM, et al. Percutaneous device closure of patent foramen ovale for secondary stroke prevention: A call for completion of randomised clinical trials. A science advisory from the American Heart Association/ American Stroke Association and the American College of Cardiology Foundation. J Am Coll Cardiol 2009;53:20I4-8.

29. Holmes DR Jr, Cohen HA, Ruiz C. Patent foramen ovale, systemic embolisation, and closure. Curr Probl Cardiol 2009;34:483-530.

30. Handke M, Harloff A, Bode C, et al. Patent foramen ovale and cryptogenic stroke: A matter of age? Semin Thromb Hemost 2009;35:505-14.

31. Negrão EM, Brandi IV, Nunes SV, et al. Patent foramen ovale and ischaemic stroke in young people: Statistical association or causal relation? Arq Bras Cardiol 2007;88:5। 4-20.

32. Handke M, Harloff A, Olschewski M, et al. Patent foramen ovale and cryptogenic stroke in older patients. N Engl J Med 2007;357:2262-8.

33. Uneo $Y$, Shimada $Y$, Tanaka $R$, et al. Patent foramen ovale with septal aneurysm may contribute to white matter lesions in stroke patients. Cerebrovasc Dis 2010; 30:15-22.

34. Homma S, Sacco RL, Di Tullio MR, et al. Effect of medical treatment in stroke patients with patent foramen ovale: Patent foramen ovale In cryptogenic stroke study. Circulation 2002; 105:2625-31.

35. Leurmans JGLM, Post HWM, ten Berg JM, et al. Complications and mid-term outcome after percutaneous patent foramen ovale closure in patients with cryptogenic stroke. Neth Heart J 2008; | 6:332-6.

36. Khairy P, O'Donnell CP, Landzberg MJ. Transcatheter closure versus medical therapy of patent foramen ovale and presumed paradoxical thromboemboli: A systematic review. Ann Intern Med 2003; 139:753-60.

37. Sacco RL, Adams R, Albers G, et al. Guidelines for prevention of stroke in patients with ischaemic stroke or transient ischaemic attack: a statement for healthcare professionals from the American Heart Association/American Stroke Association Council on Stroke: Co-sponsored by the Council on Cardiovascular Radiology and Intervention. Circulation 2006; I 13:e409-e49.

38. Messe SR, Kasner SE. Is closure recommended for patent foramen ovale and cryptogenic stroke? Patent foramen ovale in cryptogenic stroke: not to close. Circulation 2008; 1 18:1999-04

39. Ferrarini G, Malferrari G, Zucco R, et al. High prevalence of patent foramen ovale in migraine with aura. J Headache Pain 2005;6:71-6.

40. Dalla Volta G, Guindani M, Zavarise $P$, et al. Prevalence of patent foramen ovale in a large series of patients with migraine with aura, migraine without aura and cluster headache, and relationship with clinical phenotype. J Headache Pain 2005;6:328-30.
41. Carod-Artal FJ, da Silveira Ribeiro L, Braga H, et al. Prevalence of patent foramen ovale in migraine patients with and without aura compared with stroke patients: A transcranial Doppler study. Cephalgia 2006;26:934-9.

42. Schwedt $\mathrm{T}$. The migraine association with cardiac anomalies, cardiovascular disease and stroke. Neurol Clin 2009;27:513-23.

43. Dowson A, Mullen MJ, Peatfield R, et al. Migraine intervention with STARflex technology (MIST) trial: A prospective, multicentre, double-blind, sham-controlled trial to evaluate the effectiveness of patent foramen ovale closure with STARflex septal repair implant to resolve refractory migraine headache. Circulation 2008; 117:1397-04

44. Butera G, Biondi-Zoccai GL, Carminati M, et al. Systematic review and metaanalysis of currently available clinical evidence on migraine and patent foramen ovale percutaneous closure: Much ado about nothing. Catheter Cardiovasc Interv 2010;75:494-504.

45. Wahl A, Praz F, Findling $O$, et al. Improvement of migraine headaches after percutaneous closure of patent foramen ovale for secondary prevention of paradoxical embolism. Heart 2010;96:967-73.

46. Germonpre P. Patent foramen ovale and diving. Cardiol Clin 2005;23:47-52.

47. Schwerzman M, Seiler C. Recreational scuba diving, patent foramen ovale and their associated risks. Swiss Med Wkly 200 I;131:365-366.

48. Meier B. Closure of patent foramen ovale: technique, pitfalls, complications and follow-up. Heart 2005;91:444-48.

49. Kręcki R, Peruga JZ, Plewka M, et al. Implantation of an Occlutech Figulla PFO occluder in a patient with patent foramen ovale and history of embolic stroke. Cardiol J 2008; 15:380-83

50. Bijl JM, Ruygrok N, Hornung TS, et al. Percutaneous closure of patent foramen ovale. Intern Med J 2005;35:706- 10.

51. Alebegovic J, Bonvini R, Sigwart $U$, et al. The role of balloonsizing in selection of the patent foramen ovale closure device size. Exp Clin Cardiol 2008; 13:42-6.

52. El Said, McMahon CJ, Mullins CE, et al. Patent foramen ovale morphology and impact on percutaneous device closure. Pediatr Cardiol 2005;26:62-5.

53. Yared K, Baggish AL, Solis J, et al. Echocardiographic assessment of percutaneous patent foramen ovale and atrial septal defect closure complications. Circ Cardiovasc Imaging 2009;2: 141-9.

54. Motreff P, Dauphin, Souteyrand G. Cardiac perforation and tamponade 3 months after transcatheter PFO closure by STARflex device. Catheter Cardiovasc Interv 2008:71:412-416

55. Hong TE, Thaler D, Brorson J, et al.Transcatheter closure of patent foramen ovale associated with paradoxical embolism using the Amplatzer PFO occluder: Initial and intermediate term results of the U.S. multicentre clinical trial. Catheter Cardiovasc Interv 2003;60:524-28

56. Diaz T, Cubeddu RJ, Rengifo-Moreno PA, et al. Management of residual shunts after initial percutaneous patent foramen ovale closure: A single centre experience with immediate and long-term follow-up. Catheter Cardiovasc Interv 20 10;76: 145-50.

57. Majunke N, Sievert H. ASD/PFO devices: What is in the pipeline? I Interven Cardiol 2007;20:5 17-23.

58. Furlan AJ. Patent foramen and recurrent stroke: Closure is the best option? Yes. Stroke 2004;35:803-4.

59. Tong DC, Becker KJ. Patent foramen and recurrent stroke: Closure is the best option? No. Stroke 2004;35:804-5

60. Carrol JD. Double standards in the world of ASD and PFO management: Closure for paradoxical embolism. Catheter Cardiovasc Interv 2009;74: I070- I.

61. DiTullio MR. Patent foramen ovale and risk of stroke: Is there more that we should know? Eur J Neurol 2010 May 18. [E-pub ahead of print].

62. McElhinney DB. Patent foramen ovale closure. Let's keep the heart in mind. Circulation 2009; 1 19:2967-8. 